Fiddling while the ice melts?

How organizational scholars can take a more active role in the climate change debate

\author{
Shahzad (Shaz) Ansari ${ }^{1}$ \\ Judge Business School \\ University of Cambridge \\ Cambridge, CB2 1AG \\ United Kingdom \\ Phone: +44 1223768128 \\ Fax: +44 1223339701 \\ Email: $\underline{\text { s.ansari@jbs.cam.ac.uk }}$ \\ Barbara Gray \\ Management \& Org. Dept. \\ Smeal College of Business \\ Pennsylvania State University \\ 404 Business University Park, PA 16802 \\ USA \\ Phone: 814-865-3822 \\ Fax: 814-865-0123 \\ Email: b9g@psu.edu \\ Frank Wijen \\ Rotterdam School of Management \\ Erasmus University Rotterdam \\ Burg. Oudlaan 50 \\ 3062 PA Rotterdam \\ The Netherlands \\ Phone: 31104081985 \\ Fax: 31104089013 \\ Email: fwijen@rsm.nl
}

Published in: Strategic Organization, 2011, 9(1): 70-76

\footnotetext{
${ }^{1}$ The authors' names are in alphabetical order.
} 


\section{Fiddling while the ice melts? How organizational scholars can take a more active role in the climate change debate}

The debate over anthropogenic climate change or the idea that human activities are altering the physical climate of the planet continues to rage amid seemingly irreconcilable differences, both within the developed world and between developed and less developed countries. With high uncertainty, rival worldviews, and wide diversity of meaning attached to the expression, climate change has become a key narrative within which local and transnational issues - economic, social, and political - are framed and contested. The field is fraught with controversies regarding causes and consequences, as well as different attitudes toward risks, technologies, and economic and social well-being for different groups. Parties also dispute how to share responsibility for reducing emissions - whether the issue primarily needs market, regulatory, technological, or behavioral solutions. Climate change is many things to many people. Competing interests negotiate over its interpretation and utilize various strategies to promote practices that advance their own understandings regarding climate change and its governance.

Against this backdrop of widely divergent interests and views, constructing consensus around climate change at the transnational level is particularly challenging, not only because of the sheer number of players involved but also because there is no a priori, overarching governance system in place at this level that can force sovereign national governments to sign or adhere to any agreement. Policy paralysis is further exacerbated due to "future discounting", in which people find it hard to assign the same level of reality to back-of-the-mind and contested future scenarios as they do to present, immediate, tangibly visible, and front-of-the-mind issues (Giddens, 2009). It is hard to imagine, for example, how the seeming necessity of car travel today is connected to dangerous future changes in climate. Consequently, developing long-term 
policy is thwarted by demands for short-term economic prosperity, be they from politicians seeking re-election, shareholders demanding short-term profits or middle-class families trying to make ends meet. In addition, consensus is elusive since all parties are collectively responsible for climate change, even if to different degrees, and no readily identifiable villain can be held accountable. Indeed, climate change is one of the most intractable issues of our times that cannot be simply 'solved' by forging global agreements (Hulme, 2009).

The Kyoto Protocol is the most prominent embodiment of global commitments to action on climate change. While the Protocol is a proverbial Rosetta stone, crafted in the different languages of its signatories, its heavily negotiated nature has turned the agreement into a stone of contention. This is evidenced by the United States (US)' rejection of the Protocol and the internal division within the European Union (EU) about sharing the climate burden. The 2009 Copenhagen Climate Summit demonstrates that, despite protracted diplomatic efforts, high-level political involvement, and immense public pressure, no new binding global climate agreement could be reached.

The formidable social challenges posed by climate change offer a golden opportunity for social scientists to make meaningful contributions to understanding the cultural and political dimensions of this controversy. To the extent that conceptions of climate change are socially constructed (Ansari, Wijen, and Gray, 2009), the phenomenon is not as much a discrete 'problem' to be solved by reaching an acceptable level of emissions in the atmosphere but an ongoing "condition of human existence" requiring a "constructive and imaginative engagement with the idea of climate change" (Hulme, 2009: 361-364). Framed in this way, climate change offers fertile territory for organization scholars to contribute to its understanding and governance.

Climate change has already captured the attention of some sociologists and organizational scholars who have investigated the business impacts of the Kyoto regime and 
other climate policies (e.g., Giddens, 2009; Hoffman, 2006; Pinkse and Kolk, 2009), corporate responses (Levy and Egan, 2003) and reporting (Knox Hayes and Levy, this issue), and transnational governance (Engels, 2006; Wijen and Ansari, 2007). Nonetheless, we believe organizational science can provoke rethinking of some of the current notions of climate change and generate still richer insights about the cultural and institutional challenges of reaching agreements, the strategic impacts of climate change on organizations, as well as creative solutions to the challenges it raises. We invite organizational scholars to take up these challenges. To stimulate such scholarship, we propose how three well-established strands of organizational theory - institutional theory, stakeholder theory, and complexity theory - can contribute to understanding and theorizing climate change and its social and political ramifications.

\section{Bringing in organizational theories}

Since institutional theory is concerned with the symbolic and the discursive, it can be a useful foil to study climate change, which is not just a physical phenomenon but also a socially constructed (Pettenger, 2007) and contested terrain subject to competing cultural and social definitions and concomitant narratives (Ansari, Wijen, and Gray, 2009; Starkey and Crane, 2003). Institutional theory focuses on the deeper and more resilient aspects of social structure, including how social 'rules' both enable and constrain human actions (DiMaggio and Powell, 1983). Organizations often need to navigate fields characterized by multiple and conflicting institutional demands from different stakeholders or "institutional pluralism" (Pache and Santos, 2010). These generate contests over conflicting logics within organizations and across fields (Purdy and Gray, 2009; Thornton and Ocasio, 2008), which are often resolved through new institutional arrangements. Institutional scholars can explore how convergent perspectives 
among dissenting actors and collective endeavors can be reconciled, so that acting to avert climate change comes to be seen as a shared responsibility rather than someone else's problem.

A fruitful area of research is also how to deal with persistent divergence of logics, as evidenced by climate skeptics, who actively resist and discredit mitigation actions (Hoffman and Forbes, this issue): should they be ignored, co-opted, or marginalized? Getting passive actors on board is another venue for institutional scholars. Appealing framing may enroll passive actors in collective action, as may legitimacy-building tactics such as naming and shaming. For instance, rather than being framed as an environmental problem whose solution requires economic sacrifices, climate change can also be framed as an economic opportunity to attract support from reluctant parties (Gray and Stites, this issue). More agentic versions of institutional theory, grounded in notions of collective institutional entrepreneurship (Wijen and Ansari, 2007) and institutional work (Lawrence, Suddaby, and Leca, 2009), may also provide insights into how socially embedded actors can be mobilized and incentivized to engage in a collective cause. Studying the emergence of the Carbon Disclosure Project as an institutional actor that has prompted a new form of field-level governance and corporate accountability (Knox Hayes and Levy, this issue) illustrates one way in which institutional arguments can provide new insights. Scholars could also probe how institutional change in response to pressures for climate change mitigation occurs within an industry or a single corporation. Similarly, researchers could examine how initiatives taken by individual firms, such as BP's 2006 break with the Global Climate Coalition's science-skeptic stance on climate change, contribute to institutional change at the field level.

While institutional theory has traditionally focused on the symbolic, scholars have recently called for the need to also emphasize the material in order to study phenomena characterized by entanglement of the social and the material aspects of the problem (Latour, 
1987; Orlikowski, 2007). Indeed, scholars have called for "re-enchantment" with nature, as dominant anthropocentric perspectives based on human progress through exploitation of nature have led to "disenchantment" with nature (Starkey and Crane, 2003: 220). It is productive to study the interdependencies of natural and social processes (Whiteman and Cooper, forthcoming), and emphasize the networked character of human and non-human agency (Latour, 1987; Newton, 2002). Indeed, climate change lies at the intersection of two highly complex systems - the planet's biogeochemical cycles and humanity's socio-economic structures, necessitating an understanding of both the behavioral and physical impacts of climate change and policies to mitigate it.

A useful theoretical lens that could prove beneficial for strategy scholars who want to contribute to research on climate change is that of stakeholder theory. While scholars have already investigated individual firm responses to climate change (Levy and Egan, 2003; Pinkse and Kolk, 2009), new insights into corporate responses may emerge from considering how stakeholder pressure and managerial discretion work hand in hand in predicting firm responses to normative pressures, as Phillips, Berman, Elms, and Johnson-Cramer (2010) have suggested. "Both recognize that the corporation as an institution serves to meet demands - those of consumers, employees, financiers, communities and suppliers, among others" (Phillips et al., 2010: 181). Accounting for differences in sustainable performance for multinational companies within a global industry in terms of the scope of managerial discretion and the range of its stakeholders' demands placed on industry members could prove very informative. Similarly, variance in regulatory pressures by nations and regions could help to explain changes in the strategic stance of firms toward global warming. In the US, for example, institutional investors have demanded the Securities and Exchange Commission to establish new guidelines for disclosure of firms' financial risks associated with their carbon footprints. Many multinationals 
with energy-intensive operations in the EU are already subject to emission restrictions, and other regions and countries might follow suit. The shift in the origin of stakeholder demands - from environmental non-governmental organizations to governments and institutional investors - may engender different responses from multinationals. Stakeholder theory may also shed light on the power of different stakeholders in the emergence of national climate policies (Gray and Stites, this issue) or the development of climate-related practices, such as the Carbon Disclosure Project (Knox Hayes and Levy, this issue).

While institutional and stakeholder theories can generate useful insights into theorizing about climate change, recent insights from complexity theory related to non-linear dynamics (Boulton and Mitleton-Kelly, 2010; Peake, 2010)) may also prove useful. Complexity theory emphasizes deeply embedded interdependencies among the social and the material, where relatively small perturbations in environments characterized by complexity, dynamics, and diversity can trigger unpredictable regional and global shifts. For instance, climate change manifests through extreme heat and cold, which, in turn, produces deviation amplifying loops, as people burn more fossil fuels to cool or heat their buildings. Also, factors affecting global emissions (such as demographic, socio-economic, and technological change) do not readily yield to easy prediction. For example, what is the impact of deforestation in South America on flooding in South Asia? Does expanding bio-fuel production to diminish fossil fuel dependence also reduce biodiversity and food security, particularly in parts of the world that can least afford such losses? Should climate policy focus on reducing emissions generated domestically in a developed country (e.g., the US) or also include embodied carbon in products imported from emerging economies (e.g., China)?

Complexity theory provides a useful vocabulary for studying such interconnections and provides an alternative framework to the linear, reductive and Newtonian paradigm marked by 
optimal solutions and predictable outcomes that dominates policy making in this arena (Boulton and Mitleton-Kelly, 2010). In contrast to the conventional policy-making approach, rooted in the belief that humans can identify and isolate impacts, manage them, and, in turn, govern the climate system, complexity theory emphasizes the limits to predictability and highlights the need to continuously re-evaluate the appropriateness of existing climate policies against the backdrop of evolving realities - a process called reflexive or adaptive governance (Peake, 2010). Adaptive governance seeks wide participation in the policy process by cultivating broad civic engagement that can enhance the political legitimacy of, and consequent public commitment to, policy actions. From a complexity theory perspective, climate policy needs to be seen as a living, learning regime, requiring constant monitoring and reframing in the light of new evidence and changing circumstances. For example, while the share of developing countries in greenhouse gas emissions was modest when the Kyoto Protocol was concluded in 1997, the picture has since dramatically shifted, inducing a move away from historically-based targets towards contemporary responsibilities in which China is now the number one polluter. Complexity theory may also offer insights into the emergence of regional or global industry standards for "green technologies", for example, where self-reinforcing processes and threshold effects play an important role in their adoption. The disproportionally large influence of relatively small groups such as climate sceptics (Hoffman and Forbes, this issue) is another instance of nonlinear processes, thereby offering a fruitful research area: what mechanisms does a small but active group use to create societal turmoil?

\section{Getting on board}

We have argued that several organizational theories provide useful vocabularies and explanations for studying climate change and its governance. Climate change is not just a 
physical problem demanding a technical solution or a social problem demanding a political solution, but rather it touches foundational human attributes and belief systems (Hulme, 2009). Policy innovations to govern climate change have come a long way but seem inadequate to manage an issue as intractable as climate change. While market-based regimes such as the emissions trading scheme and the Carbon Disclosure Project (Knox Hayes and Levy, this issue) offer one alternative, they have been shown to be manipulable by corporate interests, while bottom-up communal solutions have limited reach and efficacy.

A combination of these approaches may be necessary, although many of these policy frameworks tend to be rooted in linear models, as if climate change can be fully understood and optimal policies devised now for its effective future governance. In that regard, policy making to some degree seems to be missing the point, since social worlds tend to resist unifying frameworks. Instead of a silver bullet, we need a "silver buckshot" - a portfolio of interventions, together with a social learning process, for understanding the evolving problem and flexible responses to address it (Prins and Rayner, 2007). These responses will need to juggle or reconcile several currently contested performance metrics for the betterment of human species, emphasizing variously economic development, environmental protection, and societal wellbeing of people around the globe. Are we, as organizational scholars, too embedded, too myopic, or too comfortable ourselves to tackle these societal challenges?

Like climate scientist and academic Hulme, we see climate change as a "provocateur", enticing us to rethink our wider social goals about how and why we live on the planet. Climate change needs to be seen as a collective "imaginative resource" shaping our individual and collective identities. Climate change can provoke us to examine the long-term implications of our short-term choices, galvanize new thinking about technology, and even challenge us to reexamine our cherished ideals of capitalism, growth, and consumption in favor of ways of living 
and doing business that are more sensitive to, and compatible with, nature. Human activities and natural phenomena will continue to intersect, leading to potentially catastrophic changes in the planet's climate, which will require commensurate human adaptive capacity. Are we, as management scholars, prepared to help construct the new narratives and take the actions needed to reconcile our human and social evolution with the physical reality of climate change? Or will we fiddle while the ice melts? 


\section{References}

Ansari, S., Wijen, F., and Gray, B. (2009) 'Averting the 'Tragedy of the Commons': An Institutional Perspective on the Construction and Governance of Transnational Commons', In G. Solomon (Ed.), Academy of Management 2009 Conference Best Paper Proceedings.

Boulton, J. and Mitleton-Kelly, E. (2010) 'Editorial - Policy and climate change', Emergence: Complexity \& Organization 12: 1-6.

DiMaggio, P. and. Powell, W. (1983) 'The Iron Cage Revisited: Institutional Isomorphism and Collective Rationality in Organizational Fields', American Sociological Review 48: 147160.

Engels, A. (2006) 'Market Creation and Transnational Rule-Making: The Case of $\mathrm{CO}_{2}$ Emission Trading', in M.-L. Djelic and K. Sahlin-Anderson (Eds.) Transnational Government: Institutional Dynamics of Regulation. Cambridge: Cambridge University Press: 329-348.

Giddens, A. (2009), The Politics of Climate Change. Cambridge, UK: Polity Press.

Goodall, A.H. (2008), 'Why have the leading journals in management (and other social sciences) failed to respond to climate change?', Journal of Management Inquiry, 17(4): 408-420.

Gray, B. and Stites, J. (2011), 'In Search of Integrative Logics: Reframing the Global Warming Debate', Strategic Organization, 9(1).

Hoffman, A. (2006) Getting Ahead of the Curve: Corporate Strategies that Address Climate Change. Arlington, VA: Pew Center on Global Climate Change.

Hoffman, A., and Forbes, M. (2011) 'The Culture and Discourse of Climate Skepticism', Strategic Organization, 9(1).

Hulme, M. (2009) Why We Disagree about Climate Change: Understanding Controversy, Inaction and Opportunity. Cambridge, UK: Cambridge University Press.

Knox Hayes, J., and Levy, D. (2011) 'The Politics of Carbon Disclosure as Climate Governance', Strategic Organization, 9(1).

Latour, B. (1987) Science in Action. Cambridge, MA: Harvard University Press.

Lawrence, T., Suddaby, R., and Leca, B. (2009) Institutional work: Actors and Agency in Institutional Studies of Organizations. Cambridge, UK: Cambridge University Press.

Levy, D. and Egan, D. (2003) 'A Neo-Gramscian Approach to Corporate Political Strategy: Conflict and Accommodation in the Climate Change Negotiations', Journal of Management Studies 40: 803-829.

Newton, T. (2002) 'Creating the New Ecological Order? Elias and Actor-Network Theory', Academy of Management Review 27: 523-540.

Orlikowski, W. (2007) Sociomaterial Practices: Exploring Technology at Work. Organization Studies 28: 1435-1448.

Pache, A-C., F. Santos (2010) 'When Worlds Collide: The Internal Dynamics of Organizational Responses to Conflicting Institutional Demands', Academy of Management Review 35: 455-476.

Peake, S. 2010. Policymaking as Design in Complex Systems: The International Climate Change Regime', Emergence: Complexity \& Organization 12(2): 15-22.

Pettenger, M. (Ed.) (2007) The Social Construction of Climate Change: Power, Knowledge, Norms. Aldershot, UK: Ashgate.

Pinkse, J. and Kolk, A. (2009) International business and global climate change. Oxford, UK: Routledge.

Phillips, R., Berman, S., Elms, H., and M. Johnson-Cramer (2010) 'Strategy, Stakeholders and Managerial Discretion', Strategic Organization 8: 176-183. 
Prins, G. and S. Rayner (2007) The Wrong Trousers: Radically Rethinking Climate Policy. Joint Research Paper. Oxford: James Martin Institute.

Purdy, J. and Gray, B. (2009) 'Conflicting Logics, Mechanisms of Diffusion and Multilevel Dynamics in Emerging Institutional Fields', Academy of Management Journal 52: 355-380.

Starkey, K. and Crane, A. (2003) 'Towards Green Narrative: Management and the Evolutionary Epic. Academy of Management Review 28(2): 220-237.

Thornton, P. and Ocasio, W. (2008) 'Institutional Logics', in R. Greenwood, C. Oliver, K. Sahlin, and R. Suddaby (Eds.) The Sage Handbook of Organizational Institutionalism. Thousand Oaks: Sage.

Whiteman, G. and Cooper, W. Forthcoming. Ecological Sensemaking. Academy of Management Journal.

Wijen, F. and Ansari, S. 2007. Overcoming Inaction through Collective Institutional

Entrepreneurship: Insights from Regime Theory. Organization Studies, 28(7): 1079-1100. 


\section{Author Biographies}

Dr. Shahzad (Shaz) Ansari (sma31@cam.ac.uk) is a University Lecturer in Strategy at the Judge Business School, University of Cambridge and Visiting Assistant Professor at the Rotterdam School of Management, Erasmus University. He is a member of the Editorial Board of Organization Science, Organization Studies, Journal of Management Studies and a full member of the Erasmus Research Institute of Management (ERIM). He is also a consulting engineer at Thinfilms Inc, a New Jersey firm providing thin film services to over 150 corporations. His research and teaching interests are: institutional change; technological and management innovations; the social construction of value; knowledge management; new market development; institutional processes in public and private fields; outsourcing and offshoring. He has published in several leading academic journals, including Academy of Management Review, Organization Science, Research Policy, Industrial and Corporate Change, Advances in Strategic Management and Organization Studies.

Dr. Barbara Gray (b9g@psu.edu) is a Professor of Organizational Behavior, Smeal Executive Programs Fellow and Director, Center for Research in Conflict and Negotiation, at The Pennsylvania State University. She holds a Ph.D. in Organizational Behavior from Case Western Reserve University. Her research interests include multiparty alliances and collaborative processes, institutional logics and change, organizational and interorganizational conflict, intercultural and interdisciplinary team dynamics and sensemaking. She has published three books and eighty other publications in journals such as Academy of Management Journal, Administrative Science Quarterly, Academy of Management Review, Organization Science, Human Relations, Journal of Applied Behavioral Science and many others. She is or has served on the editorial boards of Academy of Management Journal, Organization Science, and Journal of Applied Behavioral Science and is also a trained mediator.

Dr. Frank Wijen (fwijen@rsm.nl) is an Assistant Professor of Strategic Management at the Rotterdam School of Management, Erasmus University (the Netherlands). He holds a PhD in Management from Tilburg University, where he also worked as a Senior Researcher. Frank's research interests include organizational learning, influence and power, social networks, institutional processes, and globalization, applied to issues of environmental governance. He published in journals such as Organization Studies and $R \& D$ Management and co-edited $A$ Handbook of Globalisation and Environmental Policy, of which the second edition will shortly appear. He is an editorial board member of the Academy of Management Review and Organization Studies. 